\title{
The liaison of the young endocrine patient with the adult endocrinologist. On the occasion of a prismatic case
}

The case presented by Petzold et al in this issue ${ }^{1}$ highlights certain critical aspects of management of the child and adolescent with endocrine problems which are both of theoretical and practical interest. First, the discrepancy between the hormonal profile and the clinical manifestations, as described in this case, although not novel are, nevertheless, interesting and thought-provoking. It is evident that in this particular patient hypothalamic stimuli were not reaching the pituitary and consequently the pituitary hormones were not effectively stimulating other target glands. Among the various explanations for the apparent satisfactory clinical condition of this and other patients, ${ }^{2}$ despite the lack of therapy, could be the constitutive synthesis of the corresponding hormones by the unstimulated but intact target gland, giving rise to base-line hormone production, adequate for survival but not for well-being.

The second, more crucial aspect of this case, also encountered by many pediatric endocrinologists, 3,5 is the lack of compliance of the grown-up and especially his/her return to the pediatric endocrine clinic whenever feeling the need or the urge to see a doctor.

This attitude raises the question of how far the pediatric endocrinologist should reach out in ensuring compliance and, most importantly, in the task of

Key words: Adult endocrinologist, Liaison, Pediatric endocrine patient, Transition care accomplishing effective transition of the young patient to the care of the adult endocrinologist. Possibly, the paternal/maternal attitude expressed by the pediatric endocrinologist, who, in effect, has raised this child, is not usually manifested by the adult endocrinologist. Hence, like the patient in this report, the young adult with an endocrine problem who has 'grown up' in a pediatric endocrine center will habitually return to his/her 'home land' whenever in need to seek help.

Although specific explanations for such an attitude, as also manifested by the patient in the report of Petzold et al, are not provided, we may assume that they are analogous to those in many other cases, that is to say multiple. One explanation for young patients 'running away' could be the typical behaviour of a young adult who grew tired of the long follow-up.

Enforcing education about the problem, especially as concerns the consequences of non-compliance and of no follow-up, may prove helpful. In our experience, pamphlets, booklets and seminars aimed at young patients have proven to be of great benefit in persuading them as to the necessity for compliance and follow-up.

I thus repeat the original question, albeit without offering a satisfactory answer, namely, how far the pediatric endocrinologist should go in ensuring continuation of care and compliance for the child who has 'grown-up'.

Some endocrine units have implemented combined endocrine clinic sessions with both pediatric and adult endocrinologists for at least a certain period. ${ }^{3-5}$ Ideally, a psychologist/psychiatrist should be included 
in this group. Such an approach is likely to be more effective than simply telling the patient that he/she must now be followed in an adult endocrine clinic. If such a setting of a combined clinic is not available or feasible, we should at least refer the patient to a specific physician and monitor this patient-physician liaison to make certain that the cooperation is successful. In general, methodologies for transition must be established in accordance with local facilities.

What must be borne in mind, however, is the fact that, while individualization is important, certain guidelines must be followed.

Depending upon the nature of the problem, genetic counseling and information on the evolution of the disease under consideration should be offered by the pediatric endocrinologist once more prior to transfer. At this developmental stage, the patient will have more readiness to receive and to comprehend such knowledge.

Last but not least, I must mention that 'weaning' is difficult not only for the young patient but also for the pediatric endocrinologist, who, I suspect, somewhat subconsciously, favors return visits!

However, in each and every case, it is of at most importance that the pediatric endocrinologist act with wisdom and sensitivity in order that the transition proceeds with optimal success.

\section{Catherine Dacou-Voutetakis Editor in Chief}

\section{REFERENCES}

1. Petzold S, Keller A, Keller E, et al, 2008 A prismatic case: A 31-year old man who did not miss his pituitary. Hormones (Athens) 7: 263-270.

2. Makras P, Papadogias D, Kaltsas G, Kaklas N, Piaditis G, 2004 Growth without growth hormones $(\mathrm{GH})$ : A case report. Hormones (Athens) 3: 259-265.

3. Volta C, Luppino T, Street ME, Bernasconi S, 2003 Transition from pediatric to adult care of children with chronic endocrine diseases: a survey on the current modalities in Italy. J Endocrinol Invest 26: 157-162.

4. Stanhope R, 2004 Transition from paediatric to adult endocrinology: hypopituitarism. Growth Horm IGF Res 14: 85-88.

5. Kirk J, Clayton P, 2006 Specialist services and transitional care in paediatric endocrinology in the UK and Ireland. Clin Endocrinol (Oxf) 65: 59-63. 